\title{
BENDA ASING TELINGA HIDUNG TENGGOROK DI BAGIAN/SMF THT-KL BLU/RSUP PROF. DR. R.D. KANDOU MANADO PERIODE JANUARI 2008 - DESEMBER 2011
}

\author{
Marthalisa S. Sosir \\ Ora I. Palandeng \\ R. E. C. Tumbel \\ Bagian THT-KL Fakultas Kedokteran Universitas Sam Ratulangi Manado
Email: marthalisasosir@yahoo.co.id
}

\begin{abstract}
Sudden death, especially among children, can occur due to aspiration or the swallowing of foreign objects. Foreign objects in human organs are any kind of matter that comes from outside or inside the body, which normally is not present in these organs. This was a retrospective and descriptive study and was aimed to determine the incidence of cases of foreign objects in the ear, nose, or throat found in the Ear, Nose, and Throat - Head and Neck Department, Faculty of Medicine, University of Sam Ratulangi, Manado, from January 2008 through December 2011 in which there were 482 cases. The results showed that the highest number of cases was in 2010 (163 cases, 33.81\%), followed by 2009, 2011, and 2008. Male and female cases were $61.82 \%$ and $38.18 \%$ respectively. Cases in the age group $0-10$ years were 218 (45.22\%), followed by the age groups: >51 years, 41-50 years, 21-30 years, 31-40 years, and 11-20 years. The most usual anatomic locations of the foreign objects were the external auditory canal (58.29\%), followed by the nose, pharynx, esophagus, larynx and bronchus. Successful extractions of the foreign objects occured in $99.17 \%$ cases. Conclusion: The highest number of cases was in 2010, being more frequent in males. The most vulnerable age group was 0-10 years, and the most usual anatomic location of the foreign objects was the external auditory canal. Successful extractions of foreign objects occured in almost all cases.
\end{abstract}

Keywords: foreign objects, respiratory tract.

\begin{abstract}
Abstrak: Kematian mendadak terutama pada anak-anak dapat terjadi akibat aspirasi atau tertelan benda asing. Benda asing dalam suatu organ tubuh ialah benda yang berasal dari luar atau dalam tubuh, yang dalam keadaan normal tidak terdapat dalam organ tersebut. Penelitian ini bersifat retrospektif - deskriptif dan bertujuan untuk mengetahui insiden kasus benda asing telinga, hidung, dan tenggorok di Poliklinik THT-KL RSU Prof. Dr.R D Kandou Manado selang bulan Januari 2008- Desember 2011. Data kasus sebanyak 482 dikumpulkan secara retrospektif dari catatan medik. Jumlah kasus tertinggi pada tahun 2010 (163 kasus, 33,81\%), diikuti oleh 2009, 2011, dan 2008. Kasus laki-laki sebanyak 61,82\% dan perempuan $38,18 \%$. Kelompok usia 0-10 tahun sebanyak 218 kasus (45,22\%), diikuti kelompok usia $>51$ tahun, 41-50 tahun, 21-30 tahun, 31-40 tahun, dan 11-20 tahun. Lokasi anatomi benda asing tersering pada meatus akustikus eksterna (58,29\%), kemudian hidung, faring, esofagus, dan laring serta bronkus. Keberhasilan penatalaksanaan benda asing (ekstraksi) 99,17\%. Simpulan: Kasus benda asing pada telinga, hidung dan tenggorok tertinggi pada tahun 2010 dengan kelompok usia 0-10 tahun, jenis kelamin laki-laki, dan lokasi benda asing tersering pada meatus akustikus eksterna dengan tingkat keberhasilan ekstraksi yang tinggi.
\end{abstract}

Kata kunci: benda asing, saluran napas. 
Pada kasus benda asing masuk ke dalam saluran napas dan saluran cerna yang terjadi pada anak-anak, sepertiga dari benda asing yang teraspirasi tersangkut di saluran napas. Lima puluh lima persen dari kasus benda asing di saluran napas terjadi pada anak berusia kurang dari empat tahun. Kacangkacangan atau biji tumbuhan lebih sering teraspirasi pada anak berusia 2-4 tahun karena belum memiliki gigi molar yang lengkap dan belum dapat mengunyah makanan dengan baik. Benda asing di laring dan trakea lebih sering terjadi pada anakanak karena anak yang berusia 2-4 tahun cenderung memasukkan benda-benda yang ditemukan dan dapat dijangkaunya ke dalam liang telinga, lubang hidung dan mulut, atau dimasukkan oleh anak lain. Adanya benda asing tersebut dapat menyebabkan keadaan gawat darurat bila menyumbat saluran napas. ${ }^{1}$

Pada orang dewasa masuknya benda asing ke dalam saluran napas atau saluran cerna di sebabkan oleh kecelakaan dan kecerobohan. Sebagai contoh yaitu menelan tulang, paku (pekerja bangunan), atau jarum jahit (tukang jahit yang ketika bekerja menggigit jarum jahit dengan maksud mempercepat pekerjaan). ${ }^{2}$

Benda asing dari luar tubuh disebut eksogen dan biasanya masuk melalui mulut atau hidung. Benda asing eksogen dapat berupa zat padat (organik atau anorganik) atau cair. Zat padat organik dapat berupa tulang atau kacang-kacangan, sedangkan zat anorganik dapat berupa paku, peniti, batu, atau uang logam. Benda asing endogen dapat berupa sekret kental, darah, bekuan darah, nanah, krusta, cairan amnion, atau bronkolit. $^{3}$

Terdapat beberapa faktor yang berperan pada masuknya benda asing ke dalam telinga, hidung dan tenggorokan, yaitu: faktor personal (usia, jenis kelamin, pekerjaan, kondisi sosial, tempat tinggal); kegagalan mekanisme proteksi yang normal (tidur, kesadaran menurun, epilepsi, dan alkoholisme); faktor fisik (kelainan dan penyakit neurologik); proses menelan yang belum sempurna pada anak; faktor dental, medikal dan surgikal (tindakan bedah, ekstraksi gigi, belum tumbuhnya gigi molar pada anak yang berusia <4 tahun); faktor kejiwaan (emosi, gangguan psikis); ukuran, bentuk dan sifat benda asing; serta faktor kecerobohan (meletakkannya di mulut, persiapan makanan yang kurang baik, tergesa-gesa, makan sambil bermain). ${ }^{4}$

\section{METODOLOGI PENELITIAN}

Penelitian dilakukan di poliklinik Bagian Ilmu Kesehatan THT-KL RSU Prof. Dr. R.D. Kandou Manado pada November 2011-Januari 2012. Sampel mencakup semua penderita baru yang berobat di poliklinik THT-KL RSU Prof. R.D. Kandou Manado yang didiagnosis sebagai kasus benda asing di telinga, hidung, dan tenggorok. Pengambilan data bersifat retrospektif-deskriptif.

\section{HASIL PENELITIAN DAN BAHASAN}

Dalam kurun waktu empat tahun yaitu 2008-2011 didapatkan 482 kasus benda asing telinga, hidung, tenggorok di poliklinik THT-KL RSU Prof. Dr. R.D. Kandou Manado. Frekuensi kasus setiap tahun bervariasi (Tabel 1). Hal ini dapat dipengaruhi oleh beberapa faktor yaitu antara lain faktor personal (usia, pekerjaan, kondisi sosial, dan tempat tinggal), faktor kejiwaan seperti emosi dan gangguan psikis, serta faktor kewaspadaan orang tua dalam mengawasi anaknya terhadap benda-benda yang dapat dimasukkan ke dalam hidung, mulut atau liang telinga. Uang logam juga dapat menjadi benda asing esofagus, terutama pada anak-anak. Pencegahan dapat dilakukan dengan mempersiapkan makanan secara baik dan meletakkan benda-benda kecil yang tidak dapat dimakan jauh dari jangkauan anak-anak.

Pada orang tua, masuknya benda asing dapat disebabkan karena kecerobohan saat mengorek-ngorek kuping serta saat makan sambil bicara dan tertawa yang dapat menyebabkan teraspirasinya makanan ke dalam saluran napas. Jenis pekerjaan 
(tukang jahit, buruh bangunan) juga turut berperan dimana para pekerja mempunyai kebiasaan menggigit jarum atau paku untuk mempermudah pekerjaannya.

Tabel 1. Jumlah kasus benda asing telinga, hidung, dan tenggorok di poliklinik THT-KL RSU Prof. Dr. R.D. Kandou Manado selang tahun 2008-201.

\begin{tabular}{ccccc}
\hline No & Tahun & $\begin{array}{c}\text { Kasus } \\
\text { total }\end{array}$ & $\begin{array}{c}\text { Kasus benda } \\
\text { asing }\end{array}$ & $\mathbf{\%}$ \\
\hline 1. & 2008 & 3714 & 89 & 2,40 \\
2. & 2009 & 4031 & 129 & 3,20 \\
3. & 2010 & 5914 & 163 & 2,76 \\
4. & 2011 & 5296 & 101 & 1,91 \\
\hline
\end{tabular}

Berdasarkan kelompok usia diperoleh frekuensi masuknya benda asing tertinggi pada usia 0-10 tahun (218 kasus), diikuti oleh usia $>51$ tahun, 41-50 tahun, 21-30 tahun, 31-40 tahun, dan 11-20 tahun (Tabel 2). Hal ini disebabkan oleh keingintahuan anak-anak terhadap sesuatu benda yang baru dilihat sehingga anak-anak berusia 2-4 tahun cenderung memasukkan benda-benda di sekitarnya ke dalam lubang hidung, mulut, atau liang telinganya. Penyebab lain yaitu belum tumbuhnya gigi molar untuk dapat menelan dengan baik, koordinasi proses menelan belum sempurna, dan sfingter laring yang belum bekerja baik pada kelompok usia 6 bulan sampai 1 tahun.

Pada orang dewasa benda asing paling banyak ditemukan pada usia $>51$ tahun. Kelompok usia ini sering melalaikan sesuatu yang seharusnya tidak boleh dilakukan. Sebagai penyebabnya antara lain kecerobohan pasien yang mempunyai kebiasaan mengorek-ngorek kuping, makan sambil bicara atau tertawa, kurang berhati hati saat makan sehingga tidak memperhatikan adanya tulang dan benda-benda yang dapat termakan pada makanannya. Selain hal-hal di atas, tertelannya benda asing juga sering dialami oleh pemabuk, pemakai gigi palsu, atau penderita gangguan mental dan psikosis.

Berdasarkan jenis kelamin, pada penelitian ini didapatkan bahwa benda asing dalam liang telinga, hidung, atau tenggorokan ditemukan pada laki-laki sejumlah 298 kasus dan perempuan 184 kasus. Hal ini diduga karena laki-laki bersikap acuh tak acuh terhadap hal tersebut yang dianggap tidak penting.

Pada Tabel 3 diperlihatkan bahwa lokasi anatomi ditemukannya benda asing pada anak-anak berusia 0-10 tahun yaitu dalam lubang hidung sejumlah 104 kasus. Hal ini sesuai dengan penelitian yang menyatakan bahwa anak-anak usia tersebut cenderung memasukkan benda-benda yang ditemukan dan dapat dijangkaunya ke dalam lubang hidung, mulut, liang telinga, atau dimasukkan oleh anak lain. Pada orang dewasa lokasi anatomi ditemukannya benda asing paling sering di meatus akustikus eksterna (MAE). Dari hasil penelitian ini masuknya benda asing ke dalam MAE umumnya terjadi karena kebiasaan mengorek-ngorek kuping.

Tabel 2. Kasus benda asing telinga, hidung, dan tenggorok di poliklinik THT-KL RSU Prof. Dr. R.D. Kandou Manado berdasarkan golongan usia selang tahun 2008-2011.

\begin{tabular}{|c|c|c|c|c|c|c|c|c|c|}
\hline \multirow[t]{2}{*}{ No } & \multirow[t]{2}{*}{ Tahun } & \multicolumn{6}{|c|}{ Usia } & \multirow[t]{2}{*}{$\mathbf{N}$} & \multirow[t]{2}{*}{$\%$} \\
\hline & & $0-10$ & $11-20$ & $21-30$ & $31-40$ & $41-50$ & $>51$ & & \\
\hline 1 & 2008 & 43 & 4 & 15 & 8 & 8 & 11 & 89 & 18,54 \\
\hline 2 & 2009 & 64 & 7 & 17 & 11 & 10 & 20 & 129 & 26,80 \\
\hline 3 & 2010 & 81 & 13 & 9 & 16 & 18 & 26 & 163 & 33,61 \\
\hline 4 & 2011 & 30 & 9 & 14 & 11 & 22 & 15 & 101 & 21,05 \\
\hline \multicolumn{2}{|c|}{ Jumlah } & 218 & 33 & 55 & 46 & 58 & 72 & 482 & 100,00 \\
\hline
\end{tabular}


Tabel 3. Lokasi benda asing berdasarkan kelompok usia di Poliklinik THT-KL RSU Prof. Dr. R.D. Kandou Manado selang tahun 2008 - 2011.

\begin{tabular}{cccccccccc}
\hline No & Usia & MAE & Hidung & Faring & Laring & Esofagus & Bronkus & $\mathbf{N}$ & $\mathbf{\%}$ \\
\hline 1 & $0-10$ & 98 & 104 & 2 & 1 & 12 & 1 & 218 & 45,23 \\
$\mathbf{2}$ & $\mathbf{1 1}-\mathbf{2 0}$ & $\mathbf{2 6}$ & $\mathbf{2}$ & $\mathbf{2}$ & - & $\mathbf{3}$ & - & $\mathbf{3 3}$ & $\mathbf{6 , 8 5}$ \\
3 & $21-30$ & 45 & 1 & 6 & - & 3 & - & 55 & 11,41 \\
4 & $31-40$ & 34 & 1 & 9 & - & 2 & - & 46 & 9,54 \\
5 & $41-50$ & 38 & - & 3 & - & 7 & - & 58 & 12,03 \\
6 & $>51$ & 40 & - & 19 & - & 13 & - & 72 & 14,94 \\
\multicolumn{2}{l}{ Jumlah } & $\mathbf{2 8 1}$ & $\mathbf{1 0 8}$ & $\mathbf{5 1}$ & $\mathbf{1}$ & $\mathbf{4 0}$ & $\mathbf{1}$ & $\mathbf{4 8 2}$ & $\mathbf{1 0 0 , 0 0}$ \\
\hline
\end{tabular}

Tabel 4. Jenis benda asing yang ditemukan berdasarkan kelompok usia di Poliklinik THT-KL RSU Prof. Dr. R.D. Kandou Manado selang tahun 2008-2011.

\begin{tabular}{cccccccccc}
\hline No & $\begin{array}{c}\text { Jenis benda } \\
\text { asing }\end{array}$ & $\mathbf{0 - 1 0}$ & $\mathbf{1 1 - 2 0}$ & $\mathbf{2 1 - 3 0}$ & $\mathbf{3 1 - 4 0}$ & $\mathbf{4 1 - 5 0}$ & $>\mathbf{5 1}$ & $\mathbf{N}$ & $\mathbf{\%}$ \\
\hline 1 & Tulang & 36 & 10 & 16 & 13 & 16 & 13 & 104 & $\mathbf{2 1 , 6 0}$ \\
2 & Kapas & 18 & 7 & 13 & 10 & 14 & 17 & 79 & $\mathbf{1 6 , 4 0}$ \\
3 & Biji-bijian & 10 & 3 & - & - & 1 & - & 14 & $\mathbf{2 , 9 0}$ \\
4 & Serangga & 22 & - & 8 & 5 & 3 & 8 & 46 & $\mathbf{9 , 5 4}$ \\
5 & Batu & 14 & 5 & - & - & - & - & 19 & $\mathbf{4 , 0}$ \\
6 & Gigi palsu & - & - & - & 1 & 3 & 9 & 13 & $\mathbf{2 , 7 0}$ \\
7 & Gabus & 9 & - & - & - & - & - & 9 & $\mathbf{1 , 8 6}$ \\
8 & Kertas & 2 & - & - & - & - & - & 2 & $\mathbf{0 , 4 1}$ \\
9 & Uang logam & 4 & 1 & - & - & - & - & 5 & $\mathbf{1 , 0 3}$ \\
10 & Batang korek & 2 & - & - & 1 & - & - & 3 & $\mathbf{0 , 6 2}$ \\
11 & Manik-manik & 15 & - & - & - & - & - & 15 & $\mathbf{3 , 1 1}$ \\
12 & Kayu & 3 & - & - & 1 & - & - & 4 & $\mathbf{0 , 8 2}$ \\
13 & Paku payung & - & 1 & - & - & - & - & 1 & $\mathbf{0 , 2 0}$ \\
14 & Peluru & 15 & - & - & - & - & - & 15 & $\mathbf{3 , 1 1}$ \\
15 & Baterei & 5 & 1 & - & - & - & - & 6 & $\mathbf{1 , 2 4}$ \\
16 & Anting & 3 & - & - & - & - & - & 3 & $\mathbf{0 , 6 2}$ \\
17 & Permen & 6 & 1 & - & - & - & - & 7 & $\mathbf{1 , 4 5}$ \\
18 & Lain-lain & 54 & 4 & 18 & 15 & 21 & 25 & 137 & $\mathbf{2 8 , 4 2}$ \\
\hline
\end{tabular}

Tabel 4 memperlihatkan berbagai jenis benda asing (organik dan anorganik) yang ditemukan pada kasus-kasus di Poliklinik THT-KL RSUP Prof. Dr. R.D. Kandou Manado selang tahun 2008-2011. Pada kelompok usia 0-10 tahun jenis benda asing lebih bervariasi tetapi yang tersering ialah tulang, sedangkan pada kelompok usia $>51$ tahun yang tersering ialah kapas.

Tabel 5 memperlihatkan tingkat keberhasilan penanganan yang dilakukan di Poliklinik THT-KL RSU Prof. Dr. R.D. Kandou Manado. Dari data ini dapat dilihat bahwa tingkat keberhasilan cukup tinggi dimana dari 482 kasus benda asing dalam
Tabel 5. Persentase keberhasilan penatalaksanaan benda asing dalam telinga, hidung, dan tenggorok di Poliklinik THT-KL RSU Prof. Dr. R.D. Kandou Manado selang tahun 20082011.

\begin{tabular}{cccc}
\hline No & $\begin{array}{c}\text { Hasil } \\
\text { penatalaksanaan }\end{array}$ & $\begin{array}{c}\text { Jumlah } \\
\text { kasus } \\
(\mathbf{4 8 2})\end{array}$ & \% \\
\hline 1 & $\begin{array}{c}\text { Benda asing } \\
\text { berhasil diekstraksi } \\
\text { Benda asing tidak } \\
\text { berhasil diekstraksi }\end{array}$ & 478 & 99,17 \\
\hline
\end{tabular}

telinga, hidung dan tenggorok terdapat 478 kasus yang berhasil diekstraksi benda 
asingnya. Penanganan benda asing dalam telinga, hidung dan tenggorok tidak terlalu sulit dibandingkan penanganan benda asing di daerah laringo-faring dan esofagus dimana diperlukan alat-alat dan tehnik yang lebih memadai agar tingkat keberhasilan dapat mencapai $100 \%$.

\section{SIMPULAN}

Dari hasil penelitian dapat disimpulkan bahwa kasus benda asing pada telinga, hidung dan tenggorok di poliklinik THT-KL RSU Prof. Dr. R.D. Kandou Manado selang waktu empat tahun yaitu tahun 2008-2011 tertinggi ditemukan pada tahun 2010 dengan kelompok usia 0-10 tahun, jenis kelamin laki-laki, dan lokasi benda asing tersering pada meatus akustikus eksterna dengan tingkat keberhasilan ekstraksi yang tinggi.

\section{DAFTAR PUSTAKA}

1. Junizaf HM. Benda asing di saluran napas. In: Buku Ajar Ilmu Kesehatan Telinga Hidung Tenggorok Kepala dan Leher (Edisi Keenam). Jakarta: FKUI; 2007, p.259-65.

2. Iskandar HN. Benda asing di THT. In: Panduan Penatalaksanaan Gawat Darurat Telinga Hidung Tenggorok. Jakarta: FKUI; 2008; p.1-8.

3. Benda asing THT [homepage on the internet]. Nodate [cited 2011 Nov 5]. Available from: http://www.scribd.com/doc/ 60639131/benda-asing-tht.

4. Prabo D. Benda asing di saluran napas [homepage on the Internet]. Nodate [cited 2011 Nov 11]. Available from: http://diemazcaeem.blogspot.com/2011/ 05/benda-asing-di-saluran-napas.html. 